\title{
Roadmap 2017-2021: Stronger organization and better response to the needs of Member States in the Eastern Mediterranean Region
}

\author{
Mahmoud Fikri ${ }^{1}$
}

In October 2016, the Regional Committee for the Eastern Mediterranean Region granted me the great honour of being nominated to be the new Regional Director for the WHO Eastern Mediterranean Region (1). In January 2017, the WHO Executive Board endorsed the Regional Committee recommendation and confirmed my appointment for a five-year period beginning 1 February 2017 (2).

I have begun my new role by putting the commitments made to the Regional Committee into action; namely by establishing an Interdepartmental Taskforce to develop a clear roadmap for WHO's work in the Region during the coming five years. The establishment of the Taskforce aims to facilitate a Regional Office-wide approach to addressing the health priorities of the Eastern Mediterranean Region in a systematic and comprehensive way. In addition, it ensures that the work of the Regional Office is aligned with the needs of Member States and streamlined with the Governing Bodies' (World Health Assembly [WHA], Executive Board and Regional Committee) resolutions and decisions.

Moreover, the Taskforce has included a work plan for the preparation of this Roadmap, taking into consideration the need to involve staff at the Eastern Mediterranean Regional Office (EMRO) as well as in WHO country offices and Member States of the Region. This plan has involved a series of meetings with stakeholders, physically and virtually, to ensure active participation and fruitful contribution of staff and Member States. With this in mind, the outline framework of the Roadmap was shared with the Subcommittee of the Regional Committee during its meeting in April 2017, followed by the presentation of a draft Roadmap to Member States in the Region on 21 May 2017 in Geneva, Switzerland, just before the $70^{\text {th }}$ World Health Assembly (3); and to the heads of WHO's country offices in their meeting of 13-15 June 2017. I would expect the Roadmap to be finalized in September 2017 in order to start its implementation by October 2017.

Ultimately my vision is to increase EMRO capacity in order to meet the needs of Member States, by making $\mathrm{WHO}$ in the Region more effective, efficient, open, accountable, and transparent over the next 5 years. It is my desire to see EMRO on the front line in providing health leadership and the necessary technical and managerial support to Member States in addressing health challenges in the Region.

The Roadmap takes into consideration the global and regional environments in which EMRO is working, including the global commitment to the 2030 Agenda for Sustainable Development (4) and WHO Reform Agenda (5). Moreover, it considers the sustainable development goals (SDGs) as the overall framework guiding the work of the Organization with Member States in the Region.
While WHO ensures the consistency of this Roadmap with SDGs, I have formulated five top priority areas in order to make tangible achievements during the next five years. In addition, the Roadmap looks to promote a productive, creative and innovative environment within EMRO, with efforts focused on further development of staff skills, effective communication, appropriate coordination mechanisms, a stronger teamwork environment and enhanced delegation of authority to staff in order to promote greater accountability and transparency.

The Roadmap has been constructed on four interrelated pillars; namely joint public health priorities; enabling factors; EMRO's presence in Member States; and EMRO's working environment.

"Joint public health priorities" represent the top technical priority area that EMRO will focus on from 2017 to 2021. They are called "joint" to clearly draw attention to the fact that they cannot be addressed individually, but remain interlinked both in terms of challenges as well as strategic approaches. They include:

- Emergencies and health security; ensuring a coherent public health approach to an emergency response in crisis countries, preparedness and health security for the Region. 
- Health systems strengthening: ensuring Universal Health Coverage and for essential public health functions.

- Prevention and control of communicable diseases: addressing weaknesses in vaccination coverage and implementing integrated disease surveillance.

- Prevention and control of non-communicable diseases, mental health and substance abuse: strengthening efforts to reduce the burden and mortality by focusing on reducing their risk factors.

- Maternal, child, and adolescent health: focusing on neonatal mortality and the remaining burden of high maternal and adolescent mortality.

"Enabling factors" will emphasize the need for EMRO to deliver better on its strategic directions in order to meet Member States' expectations for support with national policies, strategies and plans of action. These principles include advocating for health in all policies; focusing on capacity building of public health management and leadership; expanding partnership with different stakeholders including the United Nations; Engaging with civil society organizations and academic institutions; enhancing regional capacities in resource mobilization, especially at country level; ensuring that monitoring and evaluation systems are established and strengthened for better performance and quality; increasing communications and advocacy to support various WHO priorities; and ensuring consideration of social and environmental determinants of health in all WHO approaches.

Since EMRO aims to strengthen and enhance its work at the country level to be more responsive to the needs of Member States, "WHO presence at country level" will represent action to be taken to implement the commitment I made to strengthen EMRO's engagement and response and to improve the image of the Organization at the country level.

"Work environment" focuses on how we can make EMRO a centre of excellence by ensuring an enabling environment to strengthen the Regional Office for efficient and effective programme implementation. I wish to see EMRO as a supporting environment for future public health leaders; to develop and attract talent; and retain staff through investment in their career development, aligned with the Region's emerging and evolving needs. Staff rotation and mobility will be utilized sensitively to ensure the needs of staff members and their families are met, while ensuring that EMRO has the right skills-set it requires.

As a results-oriented Organization, EMRO will ensure clear strategic planning in the Roadmap, including clear targets and indicators for monitoring and evaluation of all the Regional Office's important work.

Progress in addressing all areas in the Roadmap will only be possible through the sustained commitment of EMRO, its Member States, and stakeholders. It is imperative that we all unite in a combined effort to ensure a holistic improvement of health in the Region, while drawing on our well-founded existing strengths and resources. Within EMRO, a collective approach is needed to make it possible. Every individual, unit, department and office will be responsible to work in close coordination and harmony with each other to demonstrate collective responsibility, to follow the same strategic direction and guidance, and to work towards the same goal.

\section{References}

1. WHO Regional Office for the Eastern Mediterranean. Dr Fikri from United Arab Emirates nominated as WHO regional director. Cairo: WHO Regional Office for the Eastern Mediterranean; 2017 (http://www.emro.who.int/media/news/ dr-fikri-from-united-arab-emirates-nominated-for-who-regional-director.html, accessed 13 June 2017).

2. WHO Regional Office for the Eastern Mediterranean Mahmoud Fikri appointed as regional director for the WHO Eastern Mediterranean Region. Cairo: WHO Regional Office for the Eastern Mediterranean; 2017 (http://www.emro.who. $\mathrm{int} / \mathrm{media} /$ news/mahmoud-fikri-from-united-arab-emiratesappointed-as-who-regional-director-for-the-eastern-mediterranean.html, accessed 13 June 2017).
3. 70th World Health Assembly. Geneva: World Health Organization; 22-31 May 2017 (http://www.who.int/life-course/ news/events/70-wha/en/, accessed 13 June 2017).

4. United Nations. Transforming our world: the 2030 agenda for sustainable development. New York: United Nations; 2015 (https://sustainabledevelopment.un.org/post2015/transformingourworld, accessed 13 June 2017).

5. World Health Organization. WHO reform process. Geneva: World Health Organization; 2013 (http://www.who.int/ about/who_reform/process/en/, accessed 13 June 2017). 